
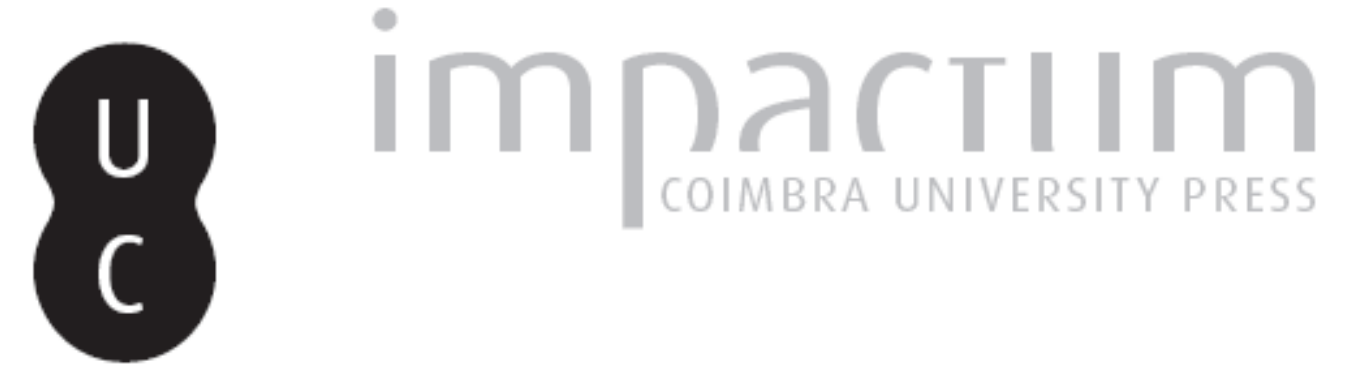

Divulgação da penicilina em Portugal na literatura técnica (anos 50 e 60 do Séc. XX): o Simposium Terapêutico e a Farmacopeia Portuguesa

Autor(es): Bell, Victoria

Publicado por: Centro de História da Sociedade e da Cultura

URL persistente:

URI:http://hdl.handle.net/10316.2/39368

DOI:

DOI:http://dx.doi.org/10.14195/1645-2259_14_10

Accessed : $\quad$ 26-Apr-2023 10:23:15

A navegação consulta e descarregamento dos títulos inseridos nas Bibliotecas Digitais UC Digitalis, UC Pombalina e UC Impactum, pressupõem a aceitação plena e sem reservas dos Termos e Condições de Uso destas Bibliotecas Digitais, disponíveis em https://digitalis.uc.pt/pt-pt/termos.

Conforme exposto nos referidos Termos e Condições de Uso, o descarregamento de títulos de acesso restrito requer uma licença válida de autorização devendo o utilizador aceder ao(s) documento(s) a partir de um endereço de IP da instituição detentora da supramencionada licença.

Ao utilizador é apenas permitido o descarregamento para uso pessoal, pelo que o emprego do(s) título(s) descarregado(s) para outro fim, designadamente comercial, carece de autorização do respetivo autor ou editor da obra.

Na medida em que todas as obras da UC Digitalis se encontram protegidas pelo Código do Direito de Autor e Direitos Conexos e demais legislação aplicável, toda a cópia, parcial ou total, deste documento, nos casos em que é legalmente admitida, deverá conter ou fazer-se acompanhar por este aviso.

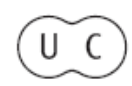




\section{4 \\ 2014}

\section{evista de História da Sociedade e da Cultura}

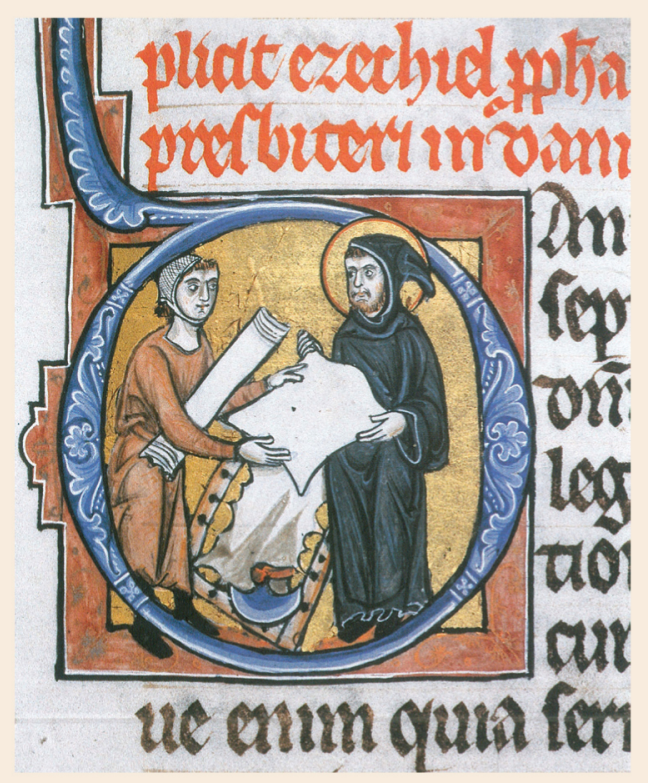

Centro de História da Sociedade e da Cultura Universidade de Coimbra 


\title{
Divulgação da penicilina em Portugal na literatura técnica (anos 50 e 60 do Séc. XX): o Simposium Terapêtico e a Farmacopeia Portuguesa
}

\author{
Victoria Bell \\ FCT (Bolsa SFRH/BD/62391/2009) \\ Faculdade de Farmácia da Universidade de Coimbra \\ victoriabel11103@gmail.com \\ Texto recebido em/Text submitted on: 03.06.2014 \\ Texto aprovado em/Text approved on: 28.10 .2014
}

\section{Resumo/Abstract:}

A penicilina foi introduzida em Portugal em Maio de 1944 pela Cruz Vermelha Portuguesa, que a começou a importar, com regularidade, a partir de Setembro desse ano. A partir de Junho de 1945, passou a ser importada através da indústria farmacêutica e foi inserida no circuito de distribuição de medicamentos. Em 1948 surgiram no mercado nacional as primeiras especialidades farmacêuticas com penicilina, manipuladas em Portugal. Em 1956, atendendo ao elevado número de medicamentos comercializados no mercado nacional e à necessidade de divulgá-los no meio foi publicado o primeiro Simposium Terapêutico, obra que, sendo um importante elemento informativo, tinha um cariz essencialmente comercial. A normalização da produção de medicamentos, a padronização de matérias-primas e a instituição de procedimentos de garantia da qualidade foram oficialmente consagradas na Farmacopeia Portuguesa. A penicilina só veio a ser incluída no Suplemento da Farmacopeia Portuguesa IV, publicado em 1961. Neste artigo pretendemos demonstrar como o Simposium Terapêutico e a Farmacopeia Portuguesa, com propósitos muito diferentes, contribuíram para valorizar os conhecimentos existentes relativos à penicilina junto dos profissionais de saúde portugueses.

Penicillin was introduced in Portugal in May 1944 by the Portuguese Red Cross, which began regularly importing this medicine in September of the same year. From June 1945 onwards, penicillin began to be imported through the pharmaceutical industry and it was introduced in the distribution chain of medicines. In 1948, the first medicinal products with penicillin, manipulated in Portugal, entered the domestic market. In 1956, in view of the high number of medicines traded in the national market and the need to publicize them among the field, the first Therapeutic Symposium was published. This work, being an important source of information, had a mainly commercial nature. The standardization of the production of medicines, the standardization of raw materials and the establishment of quality assurance procedures were officially enshrined in the Portuguese Pharmacopeia. Penicillin was only included in the Supplement of Portuguese Pharmacopeia IV, published in 1961. This paper attempts to show how the Therapeutic Symposium and the Portuguese Pharmacopeia, with very different aims, contributed to develop the existing knowledge of penicillin among the Portuguese health professionals.

Palavras chave/Keywords:

Penicilina; Simposium Terapêutico; Farmacopeia Portuguesa; História da Farmácia.

Penicillin; Therapeutic Symposium; Portuguese Pharmacopeia; History of Pharmacy. 


\section{Introdução}

É na segunda metade do século XIX, com os trabalhos de Louis Pasteur (1822-1895) e Robert Koch (1843-1910) e das suas escolas de microbiologistas que começaram a ser identificados os agentes microbianos responsáveis por variadas doenças infeciosas, sobretudo de natureza bacteriológica. Iniciou-se, também, nessa época a procura de meios para os combater ou prevenir de modo objetivo, embora se deva assinalar que o combate às doenças contagiosas e aos contágios constituía uma preocupação muito antiga. Um dos primeiros passos significativos para combater os agentes invasores microbianos foi a descoberta em 1932, por Gerhard Domagk (1895-1964) da primeira substância com propriedades antimicrobianas e com aplicabilidade terapêutica, o prontosil ${ }^{1}$. Este medicamento, considerado o primeiro de uma nova classe de fármacos antibacterianos, as sulfamidas, contribuiu para alterar profundamente o modo de encarar a utilização de fármacos no tratamento de infeções² ${ }^{2}$ Em 1928 Alexander Fleming descobriu a penicilina, mais tarde transformada em medicamento. A entrada na terapêutica das sulfamidas, por isso, foi decisiva para a aceitação da penicilina como medicamento nos anos 40 do século XX. Estas inovações surgem num período de imensas descobertas científicas no plano farmacológico e de abertura dos grupos fármaco-terapêuticos tal como hoje os conhecemos. Entre muitos exemplos refira-se em 1918 os estudos pioneiros sobre a heparina de largo interesse na terapêutica cardiovascular; em 1921 foi descoberta a insulina; no final dos anos 30 o ácido undecelénico abriu as portas à moderna terapêutica anti-micótica; as sulfonas no início dos anos 40 entraram na terapêutica anti-leprótica. A terapêutica neuropsiquiátrica surge nos anos 50 com a descoberta clorpromazina ${ }^{3}$.

1 PITA, João Rui - História da farmácia. Coimbra: MinervaCoimbra, 2007 (sobretudo o capítulo sobre o período contemporâneo). Do mesmo autor ver: Épocas de farmácia em Portugal e na Europa: sinopse histórica. Revista CEPIHS. 3 (2013) 245-267. Veja-se igualmente: PITA, João Rui; PEREIRA, Ana Leonor - A Europa científica e a farmácia portuguesa na época contemporânea. Estudos do Século XX. 2 (2002) 231-265.

2 WAINWRIGHT, Milton - Miracle cure. The story of penicillin and the golden age of antibiotics. Oxford: Basil Blackwell Ltd, 1991, p. 13.

3 Sobre a história geral da farmácia e dos medicamentos veja-se: ESTEVA DE SAGRERA, Juan - Historia de la farmácia: los medicamentos, la riqueza y el bienestar. 
Na segunda metade dos anos 40 do século XX até finais dos anos 50, a penicilina torna-se num objeto recorrente na literatura científica e técnica nacionais, à semelhança do que também se fazia no estrangeiro. Entre a literatura de natureza marcadamente técnica ou técnico-científica sobressaem em Portugal duas obras: o Simposium Terapêutico e a Farmacopeia Portuguesa. São duas obras que não têm merecido a atenção devida de estudos aprofundados de natureza histórica ${ }^{4}$. Neste $\operatorname{artigo}^{5}$ pretendemos, então, demonstrar como é que aquelas duas obras, o Simposium Terapêtico e a Farmacopeia Portuguesa, com propósitos muito diferentes, contribuíram para valorizar os conhecimentos existentes sobre a penicilina tanto junto dos profissionais de saúde portugueses como também junto da comunidade científica.

\section{A receção da penicilina em Portugal}

As propriedades terapêuticas da penicilina foram divulgadas na comunicação social a 27 de Agosto de 1942 através do artigo "Penicillium"6 publicado no jornal londrino The Times. Após o conhecimento público das propriedades do medicamento, familiares de doentes em situação crítica tentavam, por todos os meios, obter penicilina. Alexander Fleming (1881-1955), investigador responsável pela descoberta, recebeu inúmeras cartas de familiares desesperados pedindo o seu auxílio 7 . Howard Florey (1898-1968), um dos cientistas responsáveis pela transformação da penicilina em medicamento, também foi alvo desses apelos mas a inexistência de penicilina em quantidades suficientes impediram-no de poder colaborar ${ }^{8}$.

\footnotetext{
Barcelona: Masson, 2005. Veja-se, também: CHAST, François - História Contemporânea dos Medicamentos. Lisboa: Instituto Piaget, 1999.

4 No caso da farmacopeia portuguesa referimo-nos à necessidade de estudos sobre as farmacopeias portuguesas do século XX.

5 Artigo decorrente do projeto de tese da FFUC-FCT-Bolsa SFRH/BD/62391/2009 integrado no plano de trabalho do GHSCT-CEIS20-PEST-OE/HIS/UI0460/2014.

6 Penicillium. The Times. (27 $7^{\text {th }}$ August 1942).

7 MAUROIS, André - The life of Sir Alexander Fleming. Oxford: The Alden Press, 1959, p. 208.

8 BUD, Robert - Penicillin Triumph and Tragedy. Oxford: Oxford University Press, 2007, p. 59.
} 
Em Portugal os apelos para a obtenção de penicilina foram dirigidos à Cruz Vermelha Portuguesa (CVP). Esta instituição humanitária com delegações em todo o país recebeu pedidos de familiares e de clínicos de doentes para a obtenção do medicamento ${ }^{9}$. Em Março de 1944, a Direção da CVP contactou o Brasil, os Estados Unidos da América (EUA) e a Grã-Bretanha para tentar obter penicilina ${ }^{10}$. O seu pedido à Grã-Bretanha foi recusado por impossibilidade de fornecimento do medicamento ${ }^{11}$. Os EUA também manifestaram dificuldades em satisfazer o pedido português ${ }^{12}$. O Brasil, após alguma insistência da CVP, cedeu doze ampolas de penicilina a Portugal ${ }^{13}$. A penicilina oferecida pelo Brasil não foi em quantidade suficiente para satisfazer os vários pedidos do medicamento que surgiam diariamente na CVP. A instituição humanitária persistiu com o seu intento de conseguir um fornecimento regular de penicilina para Portugal, insistindo junto do governo americano, por intermédio da delegação da Cruz Vermelha Americana (CVA) em Lisboa, para que cedesse o medicamento ao nosso país ${ }^{14}$. As negociações com o governo americano foram bem sucedidas e a 2 de Setembro de 1944 o Delegado da CVA informou a CVP sobre a chegada da primeira remessa de penicilina ${ }^{15}$. A penicilina, transportada por um avião da Pan American Airways, chegou a Portugal a 8 de Setembro de 1944. No dia seguinte,

9 Arquivo da Cruz Vermelha Portuguesa, Carta enviada à Embaixada do Brasil em 27 de Março 1944. Livro de correspondência expedida, Lisboa, Vol. III, 1944. Número de ordem 1374.

${ }^{10}$ Arquivo da Cruz Vermelha Portuguesa, Ata da Sessão Ordinária da Comissão Central da Cruz Vermelha Portuguesa em 8 de Maio de 1944. Livro de atas da Comissão Central da Cruz Vermelha Potuguesa, Lisboa, 1944.

${ }^{11}$ Arquivo da Cruz Vermelha Portuguesa, Carta da Embaixada Britânica de 09 de Maio de 1944. Livro de correspondência recebida, Lisboa, 1944. Número de ordem de entrada 1800.

${ }^{12}$ Arquivo da Cruz Vermelha Portuguesa, Carta da Legação dos Estados Unidos da América de 19 de Abril de 1944. Livro de correspondência recebida, Lisboa, 1944. Número de ordem de entrada 1445.

${ }_{13}$ Arquivo da Cruz Vermelha Portuguesa, Ata da Sessão Ordinária da Comissão Central da Cruz Vermelha Portuguesa em 12 de Junho de 1944. Livro de atas da Comissão Central da Cruz Vermelha Potuguesa, Lisboa, 1944.

${ }_{14}$ Arquivo da Cruz Vermelha Portuguesa, Carta enviada à Cruz Vermelha Americana em 27 de Março de 1944. Livro de correspondência expedida, Lisboa, Vol. III, 1944. Número de ordem 1366.

${ }^{15}$ Arquivo da Cruz Vermelha Portuguesa, Carta do Delegado da Cruz Vermelha Americana em 02 de Setembro de 1944. Livro de correspondência recebida, Lisboa, 1944. Número de ordem de entrada 3728. 
o Secretário-geral da CVP, Luís de Albuquerque Bettencourt, solicitou à Direção Geral de Saúde ${ }^{16}$ autorização para "receber da Alfandega de Lisboa - Delegação do Aeroporto de Cabo Ruivo" "17 uma encomenda remetida pela “Cruz Vermelha Americana, 45, Broadway N.Y.C.". A cerimónia oficial de entrega das primeiras 700 ampolas de penicilina, vindas dos EUA, realizou-se na sede da CVP, em Lisboa, a 18 de Setembro de 1944. Estiveram presentes na cerimónia o Sr. Henry Norweb, Embaixador dos EUA e o Almirante Guilherme Ivens Ferraz, Presidente da CVP ${ }^{18}$.

Apesar de estar garantido um fornecimento regular de penicilina dos EUA, as quantidades do antibiótico disponíveis eram escassas levando à necessidade de constituição de uma comissão controladora para avaliar as requisições do medicamento recebidas na CVP. Conceituados clínicos da época foram convidados para integrarem esta comissão, a Junta Consultiva da Cruz Vermelha para a Distribuição de Penicilina em Portugal. Os membros da junta, Prof. Doutor Francisco Gentil (presidente), Doutor Luís António Xavier Júnior (secretário), Prof. Doutor Fernando da Fonseca, Prof. Doutor João Maia Loureiro e Doutor Ernesto Galeão Roma (como vogais), organizaram e supervisionaram a distribuição da penicilina recebida na CVP. Criaram um formulário específico para a requisição do antibiótico, certificaram-se de que as condições de conservação do medicamento seriam respeitadas durante o seu armazenamento ${ }^{19}$, controlaram o circuito de distribuição da penicilina através de pedidos de confirmação da receção do

${ }^{16}$ A Direcção Geral de Saúde foi criada através do Diário do Governo n. ${ }^{\circ}$ 33, de 10 de Fevereiro de 1911. Este organismo oficial tinha como função regulamentar e fiscalizar os assuntos relativos à saúde pública. Assinale-se que a Cruz Vermelha Portuguesa endereça a correspondência àquela instituição em nome de Direcção Geral de Saúde Pública.

17 Arquivo da Cruz Vermelha Portuguesa, Carta enviada à Direção Geral de Saúde Pública em 09 de Setembro de 1944. Livro de correspondência expedida, Lisboa, Vol. IX, 1944. Número de ordem 4394.

${ }^{18}$ Arquivo da Cruz Vermelha Portuguesa, Carta enviada à Direcção dos Serviços de Censura em 19 de Setembro 1944. Livro de correspondência expedida, Lisboa, Vol. IX, 1944. Número de Ordem 4482.

${ }_{19}$ Arquivo da Cruz Vermelha Portuguesa, Ata da Sessão Ordinária da Junta Consultiva da Cruz Vermelha Portuguesa para a Distribuição da Pencilina em Portugal de 26 de Julho de 1944. Livro de atas da Junta Consultiva da Cruz Vermelha Portuguesa para a Distribuição de Penicilina em Portugal, Lisboa, 1944. 
mesmo ${ }^{20}$ e, através de um impresso próprio solicitaram informações sobre o resultado do tratamento aos clínicos prescritores ${ }^{21}$.

A Junta Consultiva da Cruz Vermelha para a Distribuição de Penicilina em Portugal funcionou entre 26 de Julho de 1944 e 12 de Junho de $1945^{22}$. Durante este período distribuiu 10700 ampolas de penicilina de 100000 unidades para o tratamento de 2500 casos clínicos; 30 a $50 \%$ destas foram cedidas gratuitamente aos pobres; as ampolas que não foram cedidas gratuitamente foram vendidas por $200 \$ 00^{23}$. Apesar da Junta Consultiva ter terminado as suas funções em Junho de 1945, a CVP continuou a distribuir o medicamento até esgotar o seu stock. Encontrámos pedidos de fornecimento de penicilina à instituição em Outubro de $1945^{24}$, altura em que o medicamento já se encontrava disponível no circuito comercial ${ }^{25}$.

A penicilina foi integrada no circuito comercial de venda de medicamentos a partir de Julho de 1945. Apesar das quantidades do medicamento disponíveis para fornecimento terem aumentado, a entidade oficial reguladora do medicamento, a Comissão Reguladora dos Produtos Químicos e Farmacêuticos (CRPQF) elaborou diretivas de modo a evitar eventuais falhas no abastecimento do antibiótico. Foi elaborada uma circular com os procedimentos que deveriam ser adotados pelas farmácias na cedência de penicilina. A 13 de Julho de 1945 o Grémio Nacional das Farmácias difundiu às farmácias portuguesas o conteúdo desta circular esclarecendo-as sobre as

${ }^{20}$ Arquivo da Cruz Vermelha Portuguesa, Telegrama de José Cipriano Rodrigues Dinis de confirmação da receção de penicilina em 24 de Novembro de 1944. Cruz Vermelha Portuguesa - Junta Consultiva de Distribuição de Penicilina em Portugal, Lisboa, Vol. I, 1944/1945.

${ }^{21}$ Arquivo da Cruz Vermelha Portuguesa, Impresso para registo do resultado do tratamento com penicilina. Cruz Vermelha Portuguesa - Junta Consultiva de Distribuição de Penicilina em Portugal, Lisboa, Vol. I, 1944/1945.

${ }^{22}$ Arquivo da Cruz Vermelha Portuguesa, Carta enviada à Junta Consultiva para a Distribuição da Penicilina em Portugal em 12 de Junho 1945. Cruz Vermelha PortuguesaJunta Consultiva de Distribuição de Penicilina em Portugal, Lisboa, Vol. I, 1944/1945.

${ }^{23}$ SÃO PAYO, Marquês De - Elementos estatísticos da acção da Cruz Vermelha Portuguesa durante a guerra de 1939-1945. Boletim Oficial Cruz Vermelha Portuguesa. II, 41 (1946) 76-87.

${ }^{24}$ Arquivo da Cruz Vermelha Portuguesa, Carta do Delegado de Saúde da Anadia de 10 de Outubro de 1945. Livro de correspondência recebida, Lisboa, 1945. Número de Ordem de Entrada 11139.

${ }^{25}$ ANÓNIMO - Regulamento da venda da Penicilina. Eco Farmacêutico. 7, 58 (1945) 8. 
diretivas para a venda de penicilina nos seus estabelecimentos ${ }^{26}$. Entre 1945 e 1948, os medicamentos contendo penicilina vendidos em Portugal eram totalmente provenientes da importação, sendo os EUA o principal exportador para o nosso país ${ }^{27}$. A partir de 1947, a penicilina começou a ser importada como matéria-prima e em 1948 foram lançadas no mercado as primeiras especialidades farmacêuticas com penicilina manipuladas em Portugal. Só foi possível a manipulação do antibiótico após a instalação de uma câmara assética para o efeito ${ }^{28}$. A produção de especialidades farmacêuticas contendo penicilina em Portugal contribui para a diminuição do preço de venda ao público destes medicamentos. Em 1952, 15 laboratórios nacionais produziam medicamentos com penicilina. O laboratório Sanitas, o Instituto Pasteur de Lisboa, o laboratório Azevedos, o Instituto Luso-Fármaco, o laboratório Delta, Únitas, Nóvil, Vitória, Atral, Isis e a Companhia Portuguesa de Higiene produziam o sal sódico ou potássico de penicilina e procaína penicilina com penicilina cristalizada; os laboratórios Zimaia, Suéli, Clesus e Bial produziam somente procaína com penicilina cristalizada ${ }^{29}$. Neste ano, a venda de medicamentos contendo penicilina e estreptomicina correspondeu a $30 \%$ do total das vendas de medicamentos de produção nacional $^{30}$. Em 1966 surgiu, em Matosinhos, a primeira indústria produtora de penicilina no país a Sociedade Produtora de Leveduras Selecionadas e Micofabril ${ }^{31}$. A Sociedade Produtora de Leveduras Selecionadas era responsável pela biossíntese, extração e refinação da penicilina enquanto a Micofabril transformava a matéria-prima em especialidades farmacêuticas,

${ }^{26}$ Centro de Documentação Farmacêutica da Ordem dos Farmacêuticos - Delegação Regional de Coimbra, Circular do Grémio Nacional das Farmácia de 13 de Julho de 1945 enviada à Farmácia Cruz Viegas, Coimbra, 1945.

${ }^{27}$ COMISSÃO REGULADORA DOS PRODUTOS QUÍMICOS E FARMACÊUTICOS - Medicamentos especializados e produtos químicos medicinais. Volume I. Lisboa: Gráfica Boa Nova Ld ${ }^{\mathrm{a}}$, 1956, p. 112.

${ }^{28}$ COMISSÃO REGULADORA DOS PRODUTOS QUÍMICOS E FARMACÊUTICOS - Medicamentos especializados e produtos químicos medicinais. Volume I, cit., p. 113.

${ }^{29}$ COMISSÃO REGULADORA DOS PRODUTOS QUÍMICOS E FARMACÊUTICOS - Medicamentos especializados e produtos químicos medicinais. Volume II. Lisboa: Gráfica Boa Nova Ld ${ }^{\text {a }}$, 1956, p. 206-207.

${ }^{30}$ COMISSÃO REGULADORADOS PRODUTOS QUÍMICOS E FARMACÊUTICOS, Medicamentos especializados e produtos químicos medicinais. Volume I, cit., p. 113.

${ }^{31}$ MONTEIRO, Gilberto - Matosinhos Possui a Primeira Fábrica de Penicilina do País. Boletim da Biblioteca Pública Municipal de Matosinhos. 13 (1966) 1-8. 
embalando-as e lançando-as no mercado ${ }^{32}$. A par da Micofabril, a CipanCompanhia Industrial Produtora de Antibióticos, S.A.R.L. também deu um importante contributo para o início da produção de antibióticos em Portugal.

\section{A divulgação da penicilina no Simposium Terapêutico $(\operatorname{anos} 50-60$ do Séc. XX)}

Com a dinamização da indústria farmacêutica portuguesa e o aumento do consumo de medicamentos, o número de especialidades farmacêuticas existentes no mercado nacional aumentou significativamente. A necessidade de as divulgar de modo fidedigno junto dos profissionais de saúde levou à publicação em 1956 do primeiro Simposium Terapêutico ${ }^{33}$. Esta obra, sob a forma de livro, de carater comercial, tinha como objetivo informar médicos e farmacêuticos sobre as diversas especialidades farmacêuticas existentes no mercado, veiculando dados sobre a sua composição, indicações terapêuticas, posologia e formas de apresentação. Indicava também os laboratórios responsáveis pela sua produção e comercialização. O primeiro Simposium Terapêtico foi editado a 19 de Setembro de 1956 e teve uma tiragem de 5900 exemplares que foram distribuídos gratuitamente pela classe médica e farmacêutica. Em Fevereiro de 1955, antes da publicação do primeiro número do Simposium Terapêutico, os editores enviaram um projeto do mesmo à Ordem dos Médicos para sua apreciação. O Conselho Regional de Lisboa não teve "qualquer dúvida em considerar a ideia excelente, reputando de grande utilidade a obra em perspetiva" 34 . Os laboratórios farmacêuticos também apoiaram a iniciativa e colaboraram nos custos da publicação. A direção técnica do Simposium foi assumida pela farmacêutica Judith Lupi

${ }^{32}$ MONTEIRO, Gilberto - Matosinhos Possui a Primeira Fábrica de Penicilina do País, cit.

${ }^{33}$ NOGUEIRA, Judith Lupi; ALMEIDA, Maria Amélia Borges de (Eds.) - Simposium Terapêutico - Enciclopédia de especialidades farmacêuticas. 1. ${ }^{\circ}$ Ano. Lisboa: Editorial Ultramar, 1956.

${ }^{34}$ NOGUEIRA, Judith Lupi; ALMEIDA, Maria Amélia Borges de (Eds.) - Simposium Terapêutico - Enciclopédia de especialidades farmacêuticas. 1. ${ }^{\circ}$ Ano, cit., p. [8]. 
Nogueira e pela química farmacêutica Maria Amélia Borges de Almeida ${ }^{35}$, a administração e redação estavam sediadas em Lisboa na Travessa do Fala Só, número $15,1 .^{\circ}$ esquerdo.

O Simposium Terapêutico pretendia assumir-se como uma "enciclopédia de especialidades farmacêuticas" conforme surge em subtítulo. Na verdade, a organização da obra é muito próxima de uma enciclopédia ou de um dicionário. O primeiro ano da obra, isto é, o primeiro volume do Simposium Terapêutico encontra-se organizado em sete capítulos; no primeiro, além de uma apresentação feita pelos editores é assinalada a situação geográfica dos laboratórios nacionais e a nacionalidade dos laboratórios estrangeiros. Nesta primeira edição estão representados 47 laboratórios nacionais (41 localizados no distrito de Lisboa) e foram apresentados laboratórios de 13 países a nível mundial. O segundo, terceiro e quarto capítulos são dedicados às especialidades farmacêuticas. No capítulo II as especialidades estão organizadas por ordem alfabética sendo feita referência ao laboratório produtor e ao representante ou distribuidor; no capítulo III, também disposto alfabeticamente, é referida a composição, as indicações, a posologia e a apresentação de cada um dos medicamentos. No capítulo IV as especialidades encontram-se organizadas de acordo com a sua indicação terapêutica. No capítulo V estão descritos os laboratórios e importadores de especialidades, no capítulo VI as atividades dos colaboradores da publicação e no último capítulo são mencionadas algumas indicações gerais de utilidade médica como as unidades de medida para a administração de medicamentos, posologia segundo as diferentes idades, dados fisiológicos dos líquidos orgânicos, o tempo de incubação de várias doenças infeciosas e um calendário de gravidez.

Na nossa investigação foi efetuado um levantamento do número de especialidades farmacêuticas descritas no primeiro Simposium Terapêutico, sendo discriminadas as especialidades contendo antibióticos e nestas destacámos aquelas cuja composição inclui penicilina. As especialidades farmacêuticas com penicilina foram analisadas com maior pormenor sendo detalhadas as formas farmacêuticas em que surgem.

${ }^{35}$ Não conseguimos apurar com rigor a localização no meio científico e profissional destas duas farmacêuticas, tarefa que temos em curso. 
No Simposium Terapêutico de 1956 estão descritas 4094 especialidades farmacêuticas. Em cada uma delas está detalhada a sua composição, as indicações terapêuticas, a posologia e as apresentações em que o medicamento surge no mercado. As especialidades farmacêuticas cujo nome começa com a letra P ocorrem em maior número (409 medicamentos), circunstância que supomos ser influenciada pelo número de medicamentos contendo penicilina, cuja denominação também principia com a mesma letra. No capítulo IV do primeiro Simposium Terapêutico, dedicado à descrição das especialidades farmacêuticas segundo a sua indicação terapêutica, surgem 151 medicamentos classificados como antibióticos. Através da análise da composição dos mesmos verificámos que 104 contêm penicilina na sua formulação. A maioria dos medicamentos contendo penicilina surge no primeiro Simposium apenas com uma única forma farmacêutica descrita. No entanto, quando examinámos detalhadamente o campo dedicado à apresentação com que o medicamento se encontrava no mercado verificámos que alguns surgem em mais do que uma forma farmacêutica. Se exibirmos o resultado do estudo que efetuámos sobre os medicamentos contendo penicilina de acordo com a forma farmacêutica em que estão descritos no Simposium Terapêutico de 1956 constatamos que surgem 127 medicamentos com o fármaco, distribuídos pelas diversas formas farmacêuticas conforme exposto na tabela 1 .

Tabela 1 - Descrição das formas farmacêuticas contendo penicilina existentes no Simposium Terapêutico de 1956

\begin{tabular}{|c|c|c|}
\hline Forma farmacêutica & Ano: 1956 & $\%$ \\
\hline Comprimidos & 16 & $13 \%$ \\
\hline Gotas nasais & 1 & $1 \%$ \\
\hline Granulado & 1 & $1 \%$ \\
\hline Injetáveis & 76 & $60 \%$ \\
\hline Outros & 2 & $2 \%$ \\
\hline Óvulos & 3 & $2 \%$ \\
\hline Pastilhas & 1 & $1 \%$ \\
\hline Pensos & 1 & $1 \%$ \\
\hline Pó & 2 & $2 \%$ \\
\hline Pomada & 5 & $4 \%$ \\
\hline Pomada oftálmica & 2 & $2 \%$ \\
\hline Supositórios & 12 & $9 \%$ \\
\hline Suspensão & 5 & $4 \%$ \\
\hline Total & 127 & $100 \%$ \\
\hline
\end{tabular}


Através da representação gráfica dos dados da tabela 1 podemos com facilidade constatar que os medicamentos com penicilina na forma injetável surgem em maior número relativamente aos restantes.

Figura 1 - Gráfico das especialidades farmacêuticas contendo penicilina descritas no Simposium Terapêutico de 1956 distribuídas de acordo com a forma farmacêutica

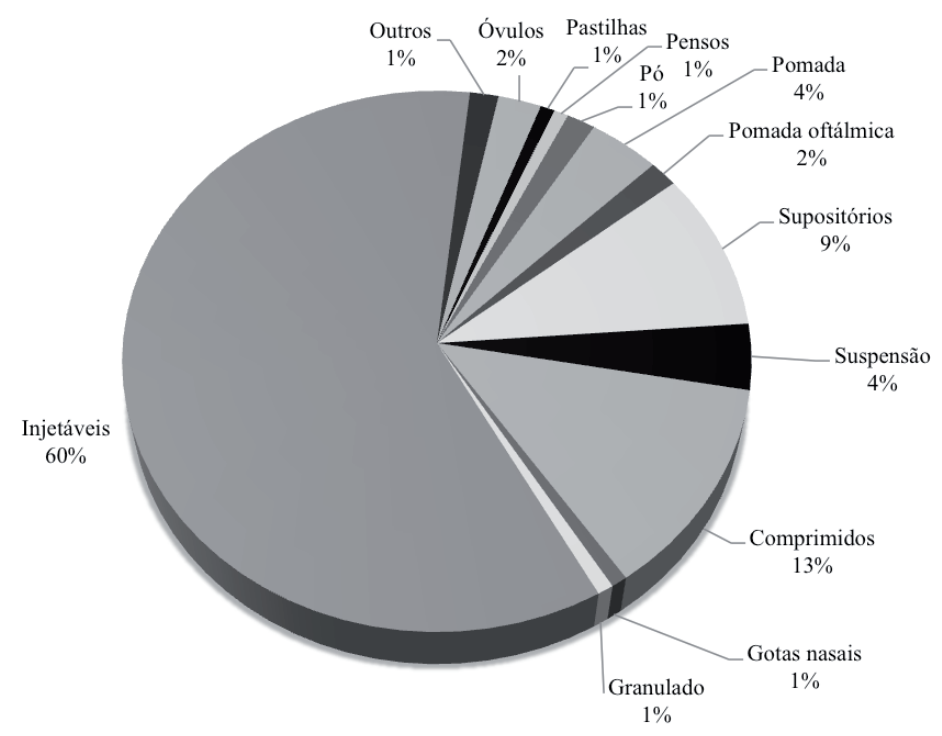

Analisando o número de especialidades farmacêuticas com penicilina relativamente ao número total de medicamentos que constam no Simposium Terapêutico de 1956 verificamos que os primeiros representam 3,1\%.

Tabela 2 - Número total de especialidades farmacêuticas existentes no Simposium Terapêutico de 1956 e número de especialidades farmacêuticas com penicilina

\begin{tabular}{|c|c|c|c|}
\hline Ano & N. $^{\text {o }}$ total medicamentos & F. farmacêuticas com penicilina & \% \\
\hline 1956 & 4094 & 127 & $3,1 \%$ \\
\hline
\end{tabular}

A publicação do primeiro Simposium Terapêutico constituiu um êxito, tendo sido reconhecida pela Ordem dos Médicos como uma publicação de "manifesto interesse" 36 e pela CRPQF como "um elemento de consulta

${ }^{36}$ NOGUEIRA, Judith Lupi (Ed.) - Simposium Terapêutico - Enciclopédia de especialidades farmacêuticas. 2. ${ }^{\circ}$ Ano. Lisboa: Sociedade Gráfica Nacional, Lda., 1957, p. [6] 
valiosa" ${ }^{37}$. Para dar continuidade à primeira edição, o Simposium Terapêutico foi novamente publicado em 20 de Novembro de 1957, com uma tiragem de 8000 exemplares. A segunda edição do Simposium Terapêutico deu continuidade à organização do primeiro mas com a direção técnica somente da farmacêutica Judith Lupi Nogueira e com agências nos Açores, em Angola e em Moçambique. Em nota, os editores esclarecem-nos que o número de laboratórios colaborantes aumentou significativamente passando a estarem inscritos na segunda edição 59 laboratórios nacionais e 116 estrangeiros. À semelhança da edição anterior, a vasta maioria dos laboratórios nacionais encontram-se situados no distrito de Lisboa; no entanto, no Simposium Terapêutico de 1957 já se encontram inscritos 2 laboratórios do distrito de Coimbra, o laboratório Minerva e o laboratório Alvim.

Apesar da organização geral da segunda edição da publicação permanecer idêntica à primeira, registámos algumas alterações na informação veiculada no capítulo IV - Especialidades por ordem de indicações terapêuticas e no capítulo V - Índice alfabético de laboratórios e importadores de especialidades; há ainda a introdução de uma secção dedicada à apresentação das alterações legislativas com maior interesse. Na segunda edição do Simposium Terapêutico as especialidades farmacêuticas surgem classificadas por grupos terapêuticos e por indicação terapêutica e a informação sobre os laboratórios e importadores de especialidades para além da morada também referencia os produtos que os laboratórios representam.

O número de especialidades farmacêuticas descritas no Simposium Terapêutico de 1957 aumentou consideravelmente em relação à edição anterior, passando a estarem incluídos 5544 medicamentos. Na segunda edição da publicação estão descritos 272 antibióticos, 210 dos quais contêm penicilina na sua composição. Quando analisámos pormenorizadamente os medicamentos contendo penicilina, apurámos que na segunda edição do Simposium Terapêutico estão presentes 240 medicamentos contendo antibiótico distribuídos pelas diferentes formas farmacêuticas de acordo com o representado na tabela 3 .

${ }^{37}$ NOGUEIRA, Judith Lupi (Ed.) - Simposium Terapêutico - Enciclopédia de especialidades farmacêuticas. 2. ${ }^{\circ}$ Ano, cit., p. [6]. 
Tabela 3 - Descrição das formas farmacêuticas contendo penicilina existentes no Simposium Terapêutico de 1957

\begin{tabular}{|c|c|c|}
\hline Forma farmacêutica & Ano: 1957 & $\%$ \\
\hline Colírio & 6 & $2,5 \%$ \\
\hline Comprimidos & 18 & $7,5 \%$ \\
\hline Gotas nasais & 2 & $0,8 \%$ \\
\hline Granulado & 1 & $0,4 \%$ \\
\hline Injetáveis & 148 & $61,7 \%$ \\
\hline Outros & 4 & $1,7 \%$ \\
\hline Óvulos & 6 & $2,5 \%$ \\
\hline Pastilhas & 6 & $2,5 \%$ \\
\hline Pensos & 1 & $0,4 \%$ \\
\hline Pó & 3 & $1,3 \%$ \\
\hline Pomada & 9 & $3,8 \%$ \\
\hline Pomada oftálmica & 5 & $2,1 \%$ \\
\hline Supositórios & 25 & $10,4 \%$ \\
\hline Suspensão & 6 & $2,5 \%$ \\
\hline Total & 240 & $100,0 \%$ \\
\hline
\end{tabular}

Relativamente à primeira edição do Simposium Terapêutico constatamos, através da Tabela 4, que, para além do incremento no número de especialidades farmacêuticas descritas, os medicamentos contendo penicilina também aumentaram substancialmente, representando $4.33 \%$ do número total de medicamentos inscritos.

Tabela 4 - Número total de especialidades farmacêuticas descritas no Simposium Terapêutico de 1957 e o número de especialidades contendo penicilina

\begin{tabular}{|c|c|c|c|}
\hline Ano & N. $^{\mathbf{0}}$ total medicamentos & F. farmacêuticas com penicilina & $\%$ \\
\hline 1957 & 5544 & 240 & $4.33 \%$ \\
\hline
\end{tabular}

De modo a comparar a evolução do número de especialidades inscritas, analisámos detalhadamente a terceira e quarta edições do Simposium Terapêutico. Na tabela 5 estão apresentados os resultados do nosso estudo. Dos dados descritos constatamos que o número de medicamentos inscritos na publicação aumentou consideravelmente de 1956 para 1958 mas que o incremento verificado para 1959 foi consideravelmente inferior. Este facto deve-se, em nosso entender, à promulgação do decreto-lei 41448 em 18 de Dezembro de 1957 no qual foram revistos os critérios de qualidade 
dos medicamentos e as normas para a introdução de novas especialidades farmacêuticas no mercado nacional.

Tabela 5 - Evolução do número de especialidades farmacêuticas inscritas no Simposium Terapêutico e número de formas farmacêuticas com penicilina

\begin{tabular}{|c|c|c|c|}
\hline Ano & N. $^{\text {o }}$ total medicamentos & F. farmacêuticas com penicilina & $\mathbf{\%}$ \\
\hline 1956 & 4094 & 127 & $3,10 \%$ \\
\hline 1957 & 5544 & 240 & $4,33 \%$ \\
\hline 1958 & 6209 & 255 & $4,11 \%$ \\
\hline 1959 & 6359 & 240 & $3,77 \%$ \\
\hline
\end{tabular}

Antes da publicação da terceira edição do Simposium Terapêutico em 1958 foi efetuado um inquérito aos clínicos de forma a melhorar a informação nele veiculada e deste inquérito resultaram algumas modificações na organização da publicação. Os medicamentos inscritos passaram a ser classificados de acordo com a sua indicação farmacológica e foram acrescentadas três rubricas: índice de águas medicinais e suas aplicações, laboratórios estrangeiros e seus representantes e preparados dietéticos, seus fabricantes e representantes ${ }^{38}$. A direção técnica da publicação, além da farmacêutica Judith Lupi Nogueira, também passou a contar com a colaboração do médico João Baptista Jacquet.

Na quarta edição do Simposium Terapêutico, em 1959, foi adotado pelos editores o slogan "dura um ano - serve todos os dias" 39 . Pensamos que a escolha deste lema pretende evidenciar a importância da publicação no quotidiano dos profissionais de saúde. No quarto Simposium Terapêutico a disposição dos capítulos sofreu algumas modificações relativamente às edições anteriores estando os assuntos apresentados de uma forma mais clara e sistematizada. O aumento da tiragem para 9000 exemplares também demonstra que a publicação constituiu um sucesso, facto que é igualmente evidenciado pelas referências entusiásticas que são salientadas pelos editores no início deste Simposium Terapêutico.

${ }^{38}$ NOGUEIRA, Judith Lupi; JACQUET, João Baptista (Eds.) - Simposium Terapêutico - Enciclopédia de especialidades farmacêuticas. 3. ${ }^{\circ}$ Ano. Lisboa: Empresa de Publicidade do Sul, 1958.

${ }^{39}$ NOGUEIRA, Judith Lupi; JACQUET, João Baptista (Eds.) - Simposium Terapêutico - Enciclopédia de especialidades farmacêuticas. 4. ${ }^{\circ}$ Ano. Lisboa: Gráfica Imperial, Lda., 1959. 
Consideramos de interesse referir a aparente ausência da publicação do Simposium Terapêutico em 1962. Desde a primeira edição, em 1956, os volumes eram publicados no final de cada ano, o que, na opinião da maioria dos laboratórios colaborantes gerava a ideia da publicação estar atrasada. Foi esta circunstância que motivou os editores a designarem de “1963” sétimo volume em vez de “1962”, passando deste modo o Simposium Terapêutico a surgir, a partir desta data, no início de cada ano e não no final ${ }^{40}$.

Na comemoração do décimo aniversário da publicação do Simposium Terapêutico, em 1966, foram introduzidas algumas alterações relevantes na sua estrutura interna. Acrescentaram-se duas novas rubricas (soluções parenterais e vacinas e soros). $\mathrm{O}$ capítulo 3 dedicado à classificação das especialidades farmacêuticas também foi modificado, passando esta a ser feita segundo a ação farmacológico-terapêutica do medicamento. De acordo com uma nota do editor, a adoção de uma classificação farmacológico-terapêutica para as especialidades farmacêuticas teve como objetivo resolver algumas dificuldades observadas por clínicos na localização de certos medicamentos em função do efeito terapêutico pretendido ${ }^{41}$. Na conceção e execução da classificação farmacológico-terapêutica foi solicitada a colaboração do clínico Manuel José da Luz. No capítulo 3, as especialidades farmacêuticas encontram-se agrupadas em vinte secções de acordo com o seu perfil farmacológico e terapêutico; para otimizar a sua pesquisa, os leitores são incentivados a consultar o "índice de classificação" 42 para determinar o sector onde se encontram os medicamentos que pretendem e, em seguida, através da designação recolhida, consultar a listagem onde se encontram as especialidades farmacêuticas pretendidas, dispostas por ordem alfabética.

${ }^{40}$ NOGUEIRA, Judith Lupi; JACQUET, João Bapista (Eds.) - Simposium Terapêutico - Enciclopédia de especialidades farmacêuticas. 7. Ano. Lisboa: Tipografia Esmeralda, Lda, 1963.

${ }^{41}$ NOGUEIRA, Judith Lupi; JACQUET, João Baptista (Eds.) - Simposium Terapêutico - Enciclopédia de especialidades farmacêuticas. 10. ${ }^{\circ}$ Ano. Lisboa: Tipografia Esmeralda, Lda, 1966.

${ }^{42}$ NOGUEIRA, Judith Lupi; JACQUET, João Baptista (Eds.) - Simposium Terapêutico - Enciclopédia de especialidades farmacêuticas. $10{ }^{\circ}$ Ano, cit. 
Na publicação da 11. a edição do Simposium Terapêutico, e na expectativa dos editores ${ }^{43}$ de melhorar a enciclopédia de especialidades farmacêuticas, foi introduzida a rubrica intitulada reagentes para análises clinicas e assegurada a colaboração técnica de 3 clínicos, da empresa Lisfarma, do Parque Vacinogénico de Lisboa, da Comissão Inter-hospitalar de Lisboa e do Instituto de Assistência Nacional aos Tuberculosos ${ }^{44}$.

A farmacêutica Judith Lupi Nogueira assumiu a direção técnica do Simposium Terapêutico em 1956, como referimos, e exerceu esta função durante 18 anos $^{45}$. A partir de 1975 a direção técnica passou a ser da responsabilidade do médico João Baptista Jacquet ${ }^{46}$ que colaborava nas funções desde 1958. Em 1975, a publicação teve uma tiragem de 14000 exemplares e tinha 7 agências, duas em Moçambique, uma nos Açores, Madeira, Angola, São Tomé e na República da Guiné-Bissau.

\section{A Farmacopeia Portuguesa e a receção da penicilina}

No âmbito da normalização da produção de medicamentos, da padronização de matérias-primas e da instituição de procedimentos de garantia da qualidade de ambos é inevitável fazer-se referência à Farmacopeia Portuguesa. A primeira farmacopeia oficial portuguesa, a Pharmacopeia Geral, consagrada nos Estatutos Pombalinos da Universidade de Coimbra de 1772, foi elaborada por Francisco Tavares, lente da Faculdade de Medicina da Universidade de Coimbra e publicada em 1794 a sua primeira edição. A utilização desta farmacopeia foi tornada obrigatória na preparação de

${ }^{43}$ NOGUEIRA, Judith Lupi; JACQUET, João Baptista (Eds.) - Simposium Terapêutico - Enciclopédia de especialidades farmacêuticas. 11. ${ }^{\circ}$ Ano. Lisboa: Gráfica Angolana, 1967

${ }^{44}$ NOGUEIRA, Judith Lupi; JACQUET, João Baptista (Eds.), Simposium Terapêutico - Enciclopédia de especialidades farmacêuticas. 11. Ano, cit.

${ }^{45}$ JACQUET, João Baptista (Ed.) - Simposium Terapêutico - Enciclopédia de especialidades farmacêuticas, 19. ${ }^{\circ}$ Ano. Lisboa: Cromotipo-artes gráficas, 1975.

${ }^{46}$ Temos em curso pesquisa para analisarmos alguns aspectos biográficos deste médico e o seu posicionamento na medicina portuguesa. 
medicamentos na botica, na prescrição de medicamentos pelos clínicos e no ensino da profissão farmacêutica nas instituições ${ }^{47}$.

Em 1935, pelo Decreto-lei n. ${ }^{\circ} 24876$ de 9 de Janeiro, foi autorizada a publicação da Farmacopeia Portuguesa $I V$, cuja primeira edição entrou em vigor em 1936 e a segunda edição revista em 1946 ${ }^{48}$. Esta foi a quarta farmacopeia oficial portuguesa, a segunda foi editada em 1835 (primeira edição) e a terceira em 1876.

A segunda edição da Farmacopeia Portuguesa IV embora tivesse sido publicada após o advento da penicilina e da sua integração na terapêutica ainda não contemplava o medicamento. A atualização dos conhecimentos contidos na farmacopeia era urgente. Tratava-se de um problema clínico e de saúde pública. Por isso, esta questão foi abordada pelo médico e político Santos Bessa num discurso proferido na Assembleia Nacional a 12 de Dezembro de 1953, onde refere ser imprescindível a "atualização da nossa farmacopeia. Temos uma farmacopeia atrasada, que não fala de antibióticos"49. Para dar seguimento à necessidade de tornar atual a nossa farmacopeia e acompanhar a evolução terapêutica foi criada pelo Decreto-lei n. ${ }^{\circ} 40$ 462, de 27 de Dezembro de 1955 a Comissão Permanente da Farmacopeia Portuguesa que teve os seus membros nomeados pela portaria publicada no Diário do Governo n. ${ }^{\circ}$ 41, 2. a série, de 19 de Fevereiro de 1957. Antes da constituição de uma comissão permanente para revisão e elaboração da Farmacopeia Portuguesa existiram outras, de carater transitório, que se dedicaram à conceção das edições anteriores da citada obra. No entanto, as constantes alterações e inovações que surgiam no domínio farmacoterapêutico levaram à necessidade de nomeação de uma comissão permanente de forma a não decorrer um período de tempo demasiadamente longo entre a publicação

${ }^{47}$ Sobre a farmacopeia portuguesa veja-se o estudo de PITA, João Rui - Um livro com 200 anos: A Farmacopeia Portuguesa (Edição oficial). A publicação da primeira farmacopeia oficial: Pharmacopeia Geral (1794). Revista de História das Ideias. 20 (1999) 47-100.

${ }^{48}$ A publicação desta quarta farmacopeia portuguesa, redigida por uma comissão onde avultavam farmacêuticos militares tem que ser entendida na política sanitária do Estado Novo e muito em particular nas medidas legislativas e regulamentares de âmbito farmacêutico dos anos 40 a 60 do século XX.

${ }^{49}$ BESSA, Santos - A medicina em S. Bento - Discurso do Dr. Santos Bessa na Assembleia Nacional - A mortalidade infantil - A luta anti-tuberculosa - Os problemas sanitários de Coimbra. O Médico. 5. 126 (1954) 57-64. 
das obras, evitando assim a desatualização dos seus conteúdos. A existência de comissões permanentes para revisão das farmacopeias em países estrangeiros também contribuiu para a implementação de uma comissão com os mesmos objetivos em Portugal. Valorizava-se, assim, o código farmacêutico português e vincava-se o interesse nacional na atualização das ciências farmacêuticas e, consequentemente, na saúde pública ${ }^{50}$.

A Comissão Permanente da Farmacopeia Portuguesa era constituída por 19 elementos e dela faziam parte representantes das Faculdades de Medicina de Lisboa, Porto e Coimbra, da Faculdade de Farmácia do Porto e das Escolas de Farmácia de Lisboa e Coimbra, da Direção Geral de Saúde, do Laboratório Militar de Produtos Químicos e Farmacêuticos, do Laboratório de Patologia Veterinária, da Faculdade de Ciências do Porto, da Ordem dos Médicos, do Sindicato Nacional dos Farmacêuticos, dos Hospitais Civis de Lisboa e dos Serviços Farmacêuticos do Hospital de Santa Maria. De forma a atualizar com a maior brevidade possível os conteúdos da Farmacopeia Portuguesa IV, esta comissão optou pela publicação de um suplemento à farmacopeia em lugar da edição de uma nova farmacopeia. Assim, em 1961, surgiu o Suplemento da Farmacopeia Portuguesa IV.

Para retratar com maior rigor científico as diversas especialidades abordadas no Suplemento da Farmacopeia Portuguesa IV foram constituídas diversas subcomissões, de Química farmacêutica, Farmacognosia, Soros e vacinas, Antibióticos, Aferições biológicas e farmacodinâmicas, Farmácia galénica e formulário, Produtos de sutura e pensos, Introdução de medicamentos novos e Redação e coordenação, constituídas por membros da Comissão de acordo com a sua área de especialização.

O suplemento à Farmacopeia Portuguesa IV foi impresso num sistema de folhas soltas, autorizado pelo Decreto-lei n. ${ }^{\circ} 42824$ de 28 de Janeiro de 1960, e que de acordo com a comissão responsável pela sua atualização seria "a forma mais conveniente de editar uma obra sujeita a tão frequentes alterações" ${ }^{51}$. O suplemento foi planificado em 12 secções organizadas de A a M, distribuídas do seguinte modo: A - Prefácio, B - Advertências,

\footnotetext{
${ }^{50}$ Farmacopeia Portuguesa IV - Suplemento, Lisboa: Imprensa Nacional de Lisboa, 1961, p. II.

${ }^{51}$ Farmacopeia Portuguesa IV - Suplemento, cit., p. IV.
} 
C - Monografias, D - Reagentes, E - Elementos de estatística, F-Métodos físico-químicos, $\mathrm{G}$ - Aferições de caráter farmacodinâmico, $\mathrm{H}$ - Métodos microbiológicos e imunológicos, I - Denominações comuns dos medicamentos, J - Tabelas, L - Legislação e M - Corrigenda e anotações à Farmacopeia Portuguesa (IV).

$\mathrm{Na}$ escolha dos fármacos a serem incluídos na farmacopeia, a Comissão teve em consideração "os fármacos cuja inclusão pareceu mais urgente pelo interesse terapêutico que apresentavam e pela necessidade de fixar as normas da sua verificação" 52 como os antibióticos. No capítulo H foram descritos “os Métodos microbiológicos e imunológicos necessários à verificação dos antibióticos assim como o Ensaio de Pirogénios e as Provas de esterilidade"53 dos mesmos.

No capítulo C do Suplemento da Farmacopeia Portuguesa IV vemos incluídas diversas monografias referentes a antibióticos. Encontram-se descritas as monografias da Bacitracina, Cloranfenicol, Cloridrato de tetraciclina, Penicilina (Benzilpeniciliato de potássio e de sódio), Penicilina benzatina, Penicilina procaína, Solução injetável de penicilina extemporânea, Solução injetável de sulfato de estreptomicina extemporânea, Sulfato de dihidroestreptomicina, Sulfato de estreptomicina, Sulfato de neomicina, Supositórios de claranfenicol, Suspensão injetável de penicilina-benzatina, Suspensão injetável de penicilina-procaína com penicilina e estreptomicina extemporânea e Suspensão injetável de penicilina-procaína com penicilina extemporânea. No capítulo H onde são descritos os métodos microbiológicos e imunológicos encontram-se especificados os métodos para a aferição biológica dos antibióticos. Para a penicilina retrata-se a penicilina sódica ou potássica e penicilina-procaína e a penicilina-benzatina, estando detalhados os meios de cultura que devem ser utilizados, o modo de preparação da suspensão bacteriana, da solução padrão, da solução da amostra, das placas e a determinação da potência.

Com a inclusão da penicilina e dos restantes antibióticos no Suplemento da Farmacopeia Portuguesa IV, o Estado colocou a sua "chancela oficial

\footnotetext{
${ }^{52}$ Farmacopeia Portuguesa IV - Suplemento, cit., p. VI.

${ }^{53}$ Farmacopeia Portuguesa IV-Suplemento, cit., p. VII.
} 
num lote de produtos necessários à produção de medicamentos" ${ }^{54}$, garantindo a implementação de normas de qualidade e contribuindo para o bom exercício da profissão farmacêutica.

A Farmacopeia Portuguesa IV vigorou até 1986 quando foi substituída pela Farmacopeia Portuguesa $V$, obra que já se encontrava em articulação com a Farmacopeia Europeia.

\section{Conclusão}

Pelo estudo que realizámos, concluímos que estas duas obras, o Simposium Terapêutico e a Farmacopeia Portuguesa, embora distintas, veicularam um capital informativo, designadamente sobre a penicilina, que muito terá auxiliado os profissionais de saúde portugueses no exercício das suas funções. O Simposium Terapêutico, com uma vertente mais comercial, compilou de forma organizada e sistematizada as diversas especialidades farmacêuticas existentes no mercado nacional, permitindo que os profissionais de saúde, médicos e farmacêuticos, acedessem de forma simplificada a informações sobre a composição, posologia e formas farmacêuticas das mesmas. Embora a publicação contasse com o apoio da indústria farmacêutica, os seus editores e diretores técnicos foram imparciais na veiculação da informação nela contida, propiciando aos seus leitores uma fonte de informação clara e fidedigna. A Farmacopeia Portuguesa, de natureza mais técnico-científica, era direcionada para os aspetos qualitativos da produção de medicamentos; difundiu normas reguladoras para verificar a qualidade das matérias-primas, para assegurar a utilização de uma formulação correta e validar as propriedades dos medicamentos produzidos, garantindo, deste modo, a qualidade dos mesmos. Neste contexto, o resultado do estudo da presença da penicilina na literatura técnica e científica referida pode ser tomado como um indicador da receção e difusão daquele medicamento junto das comunidades profissional e científica ligadas á saúde e, consequentemente, junto da comunidade.

${ }^{54}$ PITA, João Rui - A Escola de Farmácia de Coimbra (1902-1911). 1. a Edição. Coimbra: Imprensa da Universidade de Coimbra, 2009, p. 19. 